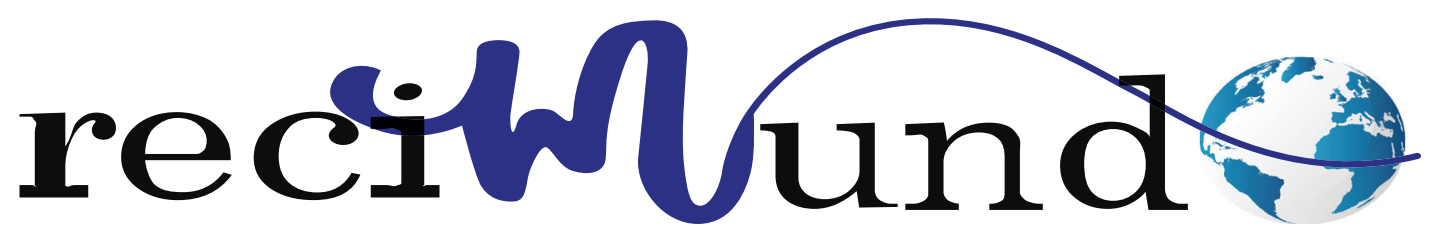

Revista Científica Mundo de la Investigación y el Conocimiento

DOI: 10.26820/recimundo/5.(Suple1).oct.2021.33-43

URL: https://recimundo.com/index.php/es/article/view/1330

EDITORIAL: Saberes del Conocimiento; Universidad Yachay Tech

REVISTA: RECIMUNDO

ISSN: 2588-073X

TIPO DE INVESTIGACIÓN: Artículo de investigación

CÓDIGO UNESCO: 32 Ciencias Médicas

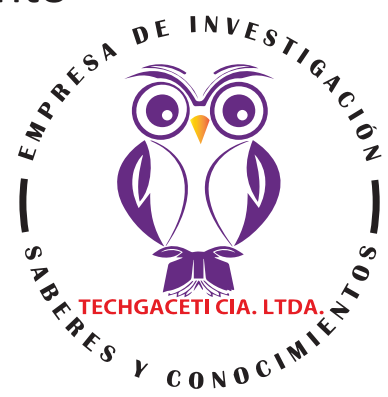

PAGINAS: 33-43

\title{
Sinergia entre la salud visual y la educación para el desarrollo sostenible
}

Synergy between visual health and education for sustainable development

Sinergia entre saúde visual e educação para o desenvolvimento sustentável

\author{
Cruz Xiomara Peraza de Aparicio ${ }^{1}$
}

RECIBIDO: 02/09/2021 ACEPTADO: 20/09/2021 PUBLICADO: 30/10/2021

1. Especialista en Medicina General de Familia; Doctora en Ciencias de la Educación; Magister en Educación Mención Planificación Educativa; Médico Cirujano; Carrera Enfermería; Universidad Metropolitana del Ecuador; Guayaquil, Ecuador; cperaza@umet.edu.ec; iD https://orcid.org/0000-0003-2588-970X

CORRESPONDENCIA

Cruz Xiomara Peraza de Aparicio

cperaza@umet.edu.ec

Guayaquil, Ecuador

( RECIMUNDO; Editorial Saberes del Conocimiento, 2021 


\section{RESUMEN}

A nivel mundial, por lo menos 2200 millones de personas tienen deficiencia visual o ceguera, de las cuales al menos 1000 millones tienen una deficiencia visual que podría haberse evitado o que aún no ha sido tratada. El aprendizaje es un proceso por el cual se incorpora o modifica una conducta y se logra un "entendimiento profundo", resultado de experiencias y prácticas que permiten al ser humano la adaptación a las exigencias del medio El objetivo del artículo es analizar la sinergia entre el ODS 3 (Salud y bienestar) y el ODS 4 (Educacion de calidad), donde ambas se encuentran interconectadas cuando se trata del ser humano, para quien salud y educación se constituyen en derechos humanos e inalienables. Material y métodos: para ello, se realizó una revisión bibliográfica, de artículos publicados en los últimos cinco años, en revistas indexadas en Google Scholar, Lilacs y Scopus. Resultados: evidente el reconocimiento científico al sistema de percepción visual como el encargado de discriminar y reconocer los estímulos visuales y de interpretarlos asociándolos a experiencias vividas. Este sistema provee las bases para que el lector adquiera estrategias de organización en la lectura que puede ejercitar cuando intenta recordar y comprender la información obtenida a partir de la decodificación. Conclusion:las patologías visuales y su detección tardía pueden culminar en consecuencias graves como la ceguera, afectando de manera significativa a la Educacion de calidad y sus metas, de ahí la necesidad d dar mayor importancia al reconocimiento de la salud visual.

Palabras clave: Salud visual; Objetivos de Desarrollo Sostenible; Dificultades de Aprendizaje; lecto-escritura

\section{ABSTRACT}

Worldwide, at least 2.2 billion people are visually impaired or blind, of which at least 1 billion have a visual impairment that could have been prevented or has not yet been treated. Learning is a process by which a behavior is incorporated or modified and a "deep understanding" is achieved, the result of experiences and practices that allow human beings to adapt to the demands of the environment. The objective of the article is to analyze the synergy between the SDG 3 (Health and well-being) and SDG 4 (Quality education), where both are interconnected when it comes to the human being, for whom health and education constitute human and inalienable rights. To do this, a bibliographic review of articles published in the last five years was carried out in journals indexed in Google Scholar, Lilacs and Scopus. Scientific recognition of the visual perception system is evident as the one in charge of discriminating and recognizing visual stimuli and interpreting them by associating them with lived experiences. This system provides the basis for the reader to acquire organizational strategies in reading that can be exercised when trying to remember and understand the information obtained from decoding, visual pathologies and their late detection can culminate in serious consequences such as blindness, affecting significantly to quality education and its goals, hence the need to give greater importance to the recognition of visual health.

Keywords: Visual health; Sustainable Development Goals; Learning difficulties; reading-writing.

\section{RESUMO}

Em todo o mundo, pelo menos 2,2 bilhões de pessoas são deficientes visuais ou cegas, das quais pelo menos 1 bilhão têm uma deficiência visual que poderia ter sido prevenida ou ainda não tratada. Aprender é um processo pelo qual um comportamento é incorporado ou modificado e uma "compreensão profunda" é alcançada, resultado de experiências e práticas que permitem ao ser humano se adaptar às demandas do meio ambiente. O objetivo do artigo é analisar a sinergia entre o ODS 3 (Saúde e bem-estar) e o ODS 4 (Educação de qualidade), onde ambos estão interligados no que diz respeito ao ser humano, para quem saúde e educação constituem humanos e inalienáveis. direitos. Para tanto, foi realizada uma revisão bibliográfica de artigos publicados nos últimos cinco anos em periódicos indexados no Google Scholar, Lilacs e Scopus. O reconhecimento científico do sistema de percepção visual é evidente como o encarregado de discriminar e reconhecer os estímulos visuais e interpretá-los associando-os às experiências vividas. Este sistema fornece a base para o leitor adquirir estratégias organizacionais na leitura que podem ser exercitadas ao tentar lembrar e compreender as informações obtidas na decodificação, patologias visuais e sua detecção tardia podem culminar em graves consequências como a cegueira, afetando de forma significativa para uma educação de qualidade. e seus objetivos, daí a necessidade de dar maior importância ao reconhecimento da saúde visual.

Keywords: Saúde visual; Metas de desenvolvimento sustentável; Aprendendo dificuldades; leitura / escrita. 


\section{Introducción}

El ser humano cuenta anatómica Y fisiológicamente con cinco sentidos, de los cuales el más desarrollado de ellos es el sentido de la vista, considerado el más importante de todos. Esto se debe, en parte, a que el hombre vive en un mundo en el que históricamente se le ha dado prioridad a lo visual y a las imágenes.

De hecho, diversos estudios entre ellos los de Yuste y Church (2014) señalan que casi el $50 \%$ de la actividad cerebral se dedica a procesar las imágenes provenientes de la realidad y que, además, el grueso de las experiencias sensoriales que tiene el hombre son visuales, en un estudio ampliamente divulgado que identificó neuronas individuales que se activaban ante la visión del rostro de una conocida actriz, para su reconocimiento lo permitía ese grupo de neuronas sensibilizadas por la imagen.

Las patologías de la visión y de los ojos no tienen síntomas o signos externos, por lo que es fácil no ser consciente de que existen problemas.

La práctica de cuidados preventivos a través de exámenes periódicos de los mismos, permitirán el diagnóstico y tratamiento temprano de dichos problemas, todo orientado a mantener una buena visión y salud ocular y, cuando sea posible, para prevenir la pérdida de la visión.

El interés del presente estudio se centra básicamente en dos aspectos fundamentales, en primer lugar, los efectos de los problemas visuales en el aprendizaje la importancia de prevenir dificultades relativas a la funcionalidad visual que repercutan de manera negativa en el rendimiento estudiantil, en segundo lugar, en la necesidad de estudiar la influencia de la salud visual en la educación para el desarrollo sostenible, estableciendo esa íntima relación entre la salud y la educación.
La UNESCO (2021) tiene como objetivo mejorar el acceso a una educación sobre el desarrollo sostenible de calidad a todos los niveles y en todos los contextos sociales, para transformar la sociedad al reorientar la educación y ayudar a las personas a desarrollar los conocimientos, habilidades, valores y comportamientos necesarios para el desarrollo sostenible, donde se pone de manifiesto la necesidad imperante de gozar de una buena salud visual. De ahí el objetivo del artículo en analizar la sinergia entre el ODS 3 (Salud y bienestar) y el ODS 4 (Educacion de calidad), donde ambas se encuentran interconectadas cuando se trata del ser humano, para quien salud y educación se constituyen en derechos humanos e inalienables.

\section{Metodología}

Desde el punto de vista del planteamiento metodológico, esta investigación es de tipo documental; lo que se ha hecho es elaborar un estado del arte en el que se analiza el fenómeno de la investigación que se requiere la sinergia entre el ODS 3 y el ODS 4 que entrelaza la salud con la educación, para un desarrollo sostenible. La ruta metodológica que se ha seguido ha comprendido básicamente tres momentos: exploración, focalización y profundización. Se revisaron 30 artículos de las bases de datos de revistas indexadas de los cuales se consideraron 10 Los criterios de inclusión comprenden: uso de los descriptores: salud visual, aprendizaje, objetivos de desarrollo sostenible, educación para el desarrollo sostenible; así como artículos publicados en revistas indexadas en los últimos cinco años.

\section{Desarrollo}

\section{1.-Vision y aprendizaje}

De los órganos de los sentidos, la visión se considera fundamental en el aprendizaje, ya que constituye uno de los dos canales importantes de entrada de información en los seres humanos, de ahí que, un fallo en el 
sistema visual del niño producirá un retraso en su aprendizaje escolar en general y en la lectoescritura en particular, y esto no solo puede afectar al niño sino al individuo en etapas más avanzadas como en la secundaria e inclusive en la universidad.

Considerando que la vision según Fransoy y Augé (2013) es un proceso neurológico complejo que integra todas las habilidades visuales con el objetivo de identificar, interpretar y comprender cada uno de los estímulos que penetran en el sistema visual.

Fransoy y Augé (ob, cit 2013) describen la presencia de diferentes habilidades visuales, que se muestran a continuación:

\section{1.- Relacionadas con la función visual:}

- Agudeza visual: Hace referencia al valor cuantitativo de la visión, es decir, la capacidad de distinguir detalles pequeños a una determinada distancia

- Refracción ocular: La condición refractiva es la capacidad del ojo de enfocar la imagen en la retina

- Visión del color: Cuando existen dificultades en distinguir los colores y sus matices

\section{2.- Relacionadas con la eficacia visual:}

- Motilidad ocular: Es la habilidad para seguir un objeto en movimiento dentro del campo visual (movimientos de seguimiento) y la capacidad para saber dirigir los ojos de forma rápida y eficaz de un estímulo a otro (movimientos sacádicos).

- Acomodación: Es la habilidad que permite mantener el enfoque en diferentes actividades en visión cercana como la lectura y la escritura. La flexibilidad acomodativa es la que permite enfocar rápidamente al cambiar la mirada de un estímulo a otro, situados a diferentes distancias.

- Binocularidad: Es la habilidad que permite utilizar los dos ojos de manera coordinada y simultánea y que, en perfectas condiciones, da paso la estereopsia o visión en 3D.

\section{3.- Relacionadas con la percepción vi- sual:}

- Atención visual y atención visual mantenida: Es la capacidad de hacer una actividad de forma continua sin interferencias externas.

- Procesamiento de la información visual: Es un conjunto de habilidades que permiten discriminar, visualizar y archivar en memoria las imágenes que percibe el sistema visual.

- Visión periférica: Es la capacidad que nos permite ser conscientes de lo que pasa al alrededor mientras se está realizando una actividad específica.

\section{4.- Habilidades de integración sensorial:}

- Integración viso-espacial: Permite entender el espacio, situarse en él y así localizar objetos y calcular distancias. Tres son las habilidades relacionadas con este concepto:

- Lateralidad: Permite tener conciencia interna de los dos lados del cuerpo y saber diferenciarlos (gracias a las informaciones que llegan del sistema vestibular, propioceptivo y visual, como veremos más adelante).

- Direccionalidad: Tener conciencia y diferenciar derecha-izquierda en el espacio exterior tridimensional.

- Integración bilateral: Es la habilidad que nos permite ser conscientes de las dos partes del cuerpo separada y simultáneamente. En esta habilidad es relevante la función del cuerpo calloso del cerebro.

- Integración viso-motora: Permite integrar las habilidades visuales y perceptivas con el control postural y conseguir control del movimiento motor, propiciando la base para el control manual fino.

- Integración viso-auditiva: Permite relacionar lo que se escucha con lo que se ve.

- Es la capacidad para igualar la distribución temporal de un estímulo auditivo a la distribución espacial de un estímulo visual. Es también la capacidad de integrar 
la información aferente visual y auditiva y la correspondiente respuesta eferente oral y escrita.

Más de mil millones de personas en todo el mundo viven con deficiencia visual porque no reciben la atención que necesitan para afecciones como la miopía, la hipermetropía, el glaucoma y las cataratas, según el primer Informe mundial sobre la visión publicado por la Organización Mundial de la Salud (OMS,2019). A nivel mundial, por lo menos 2200 millones de personas tienen deficiencia visual o ceguera, de las cuales al menos 1000 millones tienen una deficiencia visual que podría haberse evitado o que aún no ha sido tratada.

La carga de enfermedades oftalmológicas y deficiencias visuales, la OMS (2019) no afecta a todas las personas por igual: a menudo afecta mucho más a las personas que viven en zonas rurales, a aquellas con bajos ingresos, a las mujeres, a las personas mayores, a las personas con discapacidad, a las minorías étnicas y a las poblaciones indígenas. Se estima que la necesidad insatisfecha de atención de la miopía en las regiones de ingresos bajos y medios es cuatro veces mayor que en las regiones de ingresos altos.

El proceso de aprendizaje del ser humano durante la infancia, se sustenta en un $80 \%$ en la información percibida por medio del sentido de la vista. Los defectos visuales no tratados en los niños, implica un bajo rendimiento escolar, dificultades en el aprendizaje y retraso en su desarrollo psicosocial. Expertos de la Clinica Cofán (2018) refieren que, un tratamiento oportuno de los defectos visuales en la población infantil promueve su recuperación y evita el desarrollo de discapacidades visuales cuando el niño llega a la edad adulta.

A continuación, se presentan una serie de artículos que hacen referencia a la importancia de la vision en el aprendizaje. (Cuadro 1) 
Cuadro 1. Visión y Aprendizaje

\begin{tabular}{|c|c|c|}
\hline HALLAZGOS & ARTÍ́CULOS & ANÁLISIS \\
\hline $\begin{array}{l}\text { A fin que los estudiantes sean } \\
\text { protagonistas y constructores de } \\
\text { sus aprendizajes el uso del Visual } \\
\text { Thinking permite desarrollar el } \\
\text { pensamiento visual, como dimen- } \\
\text { sión cognitiva fundamental para } \\
\text { abordar textos y representar sus } \\
\text { comprensiones recurriendo a una } \\
\text { serie de imágenes que ilustran } \\
\text { ideas textualizadas, ya sean en } \\
\text { escritas u orales. }\end{array}$ & \begin{tabular}{|l|} 
\\
Visual Thinking una alternativa in- \\
novadora en los procesos de en- \\
señanza- aprendizaje de Estudios \\
Sociales \\
(Pinargote,2021)
\end{tabular} & $\begin{array}{l}\text { Aquí se reafirma la importancia } \\
\text { que tienen las habilidades visuales } \\
\text { y la conexiones neurocognitivas } \\
\text { como vías que contribuyen desde } \\
\text { la creatividad y la innovación con } \\
\text { el proceso de aprendizaje en es- } \\
\text { tos tiempos de digitalización. }\end{array}$ \\
\hline $\begin{array}{l}\text { Cuando la pérdida de vista se } \\
\text { debe a una enfermedad rara de la } \\
\text { visión, a los efectos negativos de } \\
\text { ésta en la persona que la padece, } \\
\text { se suman factores estresantes re- } \\
\text { lacionados con la etiología genéti- } \\
\text { ca, incluidos los riesgos para otros } \\
\text { miembros de las familias, riesgos } \\
\text { reproductivos y la culpa y el sen- } \\
\text { timiento de culpabilidad de los } \\
\text { padres. Los jóvenes con Sindrome } \\
\text { de Usher, manifestaron que pade- } \\
\text { cer la enfermedad ha influido en la } \\
\text { elección de la carrera universitaria } \\
\text { o de su profesión. }\end{array}$ & \begin{tabular}{|l|} 
\\
La importancia de los registros \\
de pacientes con Enfermedades \\
Raras de la visión para la investi- \\
gación en ciencias sociales (Del \\
Alamo,2021) \\
\end{tabular} & $\begin{array}{l}\text { Se requiere dar a conocer estas } \\
\text { enfermedades raras asociadas } \\
\text { a factores genéticos, que cursan } \\
\text { con patologías visuales que son } \\
\text { poco conocidas y que afectan a } \\
\text { este sector de la población que } \\
\text { como grupo minoritario recibe } \\
\text { poca atención por desconocimien- } \\
\text { to de los actores sociales involu- } \\
\text { crados en la situación. } \\
\text { La Neuroeducación es una disci- } \\
\text { plina académica joven donde con- } \\
\text { vergen las neurociencias, la psico- } \\
\text { logía cognitiva y la educación. Las } \\
\text { investigaciones en neurociencias } \\
\text { muestran que algunos marcado- } \\
\text { res neurales, como la conectividad } \\
\text { del fascículo arqueado, son muy } \\
\text { útiles y eficaces en la predicción } \\
\text { de las trayectorias de desarrollo y } \\
\text { aprendizaje de niños y niñas, así } \\
\text { como en sus } \\
\text { respuestas a la enseñanza }\end{array}$ \\
\hline $\begin{array}{l}\text { Los primeros años de vida son una } \\
\text { etapa crítica para el desarrollo vi- } \\
\text { sual. Por ello, una buena vision } \\
\text { en edades tempranas es impres- } \\
\text { cindible para el desarrollo social } \\
\text { y educacional y fundamental para } \\
\text { potenciar el aprendizaje y el rendi- } \\
\text { miento durante la etapa escolar y } \\
\text { años posteriores. }\end{array}$ & $\begin{array}{l}\text { La Salud Visual Infantil Desde la } \\
\text { Atención Primaria. Un Caso de } \\
\text { Estudio en la Enseñanza de Op- } \\
\text { tometría (Peraza de Aparicio et } \\
\text { al,2020). }\end{array}$ & $\begin{array}{l}\text { Se requiere desde el nivel de aten- } \\
\text { ción primaria la promocion de la } \\
\text { salud visual desde tempranas } \\
\text { edades, con énfasis en los esco- } \\
\text { lares, para detectar fallas visua- } \\
\text { les que de detectarse a tiempo } \\
\text { pueden dar respuestas oportunas, } \\
\text { conductas hiperactivas en el niño } \\
\text { que interfieren con su aprendizaje } \\
\text { y rendimiento escolar. }\end{array}$ \\
\hline
\end{tabular}




\begin{tabular}{|c|c|c|}
\hline $\begin{array}{l}\text { Las luces LED se encuentran en } \\
\text { las pantallas retroiluminadas y tam- } \\
\text { bién en la iluminación ambiental, la } \\
\text { luz azul se asocia directamente al } \\
\text { aumento de la difusión de la luz } \\
\text { intraocular, lo que adquiere mayor } \\
\text { importancia cuando hay una falta } \\
\text { de transparencia de los medios, } \\
\text { como con la queratitis derivada de } \\
\text { los ojos secos } \\
\text { o en el caso de cataratas relacio- } \\
\text { nadas con la edad. }\end{array}$ & $\begin{array}{l}\text { Luz azul: de las evidencias científi- } \\
\text { cas a la atención al paciente. (Gar- } \\
\text { cía, } \vee, 2017 \text { ) }\end{array}$ & $\begin{array}{l}\text { Los avances tecnológicos de este } \\
\text { tipo de luces hacen énfasis en el } \\
\text { ahorro energético que trae implíci- } \\
\text { to su uso, Por otra parte, la luz azul } \\
\text { puede dañar el ojo al emitir una ra- } \\
\text { diación altamente energética ca- } \\
\text { paz de destruir fotorreceptores y } \\
\text { otras células de la retina. Y lo que } \\
\text { es más preocupante: es, además, } \\
\text { un factor de riesgo para glauco- } \\
\text { ma, degeneración macular aso- } \\
\text { ciada a la edad u otras patologías } \\
\text { que pueden derivar en ceguera. }\end{array}$ \\
\hline
\end{tabular}

Fuente: Artículos revisados Aparicio,2021

\section{2.-Educacion y los Objetivos de Desarro- llo Sostenible}

En calidad de organización de las Naciones Unidas especializada en educación, la UNESCO (2021), ha recibido el encargo de dirigir y coordinar la Agenda de Educación 2030. Este programa forma parte de un movimiento mundial encaminado a erradicar la pobreza mediante la consecución, de aquí a 2030, de 17 Objetivos de Desarrollo Sostenible (Organización de las Naciones Unidas, ONU 2015), la educación, fundamental para alcanzar todos estos objetivos, cuenta con su propio objetivo específico, el ODS 4, que se ha propuesto "garantizar una educación inclusiva, equitativa y de calidad y promover oportunidades de aprendizaje durante toda la vida para todos". El Marco de Acción de Educación 2030 ofrece orientación para la aplicación de este ambicioso objetivo y sus compromisos.

Los Objetivos de Desarrollo Sostenible (ONU,2019) pretenden ampliar los Objetivos de Desarrollo del Milenio (ODM) y alcanzar aquellos objetivos que no se cumplieron. La idea central es que todos los países, con independencia de su nivel de desarrollo o riqueza, se comprometan a promover la prosperidad y a proteger el medioambiente. Los Objetivos de Desarrollo Sostenible no son obligatorios pero cada país asume la responsabilidad de trabajar por su cumplimiento.
Desde 1992, la UNESCO (2021), ha promovido la Educación para el Desarrollo Sostenible (EDS). Entre 2005 y 2014, coordinó el Decenio de las Naciones Unidas de la EDS, y ahora está llevando a cabo el programa de seguimiento, el Programa de Acción Mundial sobre la EDS.

El impulso de la EDS nunca ha sido más fuerte. Temas mundiales -como el cambio climático- requieren de forma urgente un cambio en los estilos de vida y una transformación en la forma de actuar y pensar. Para lograrlo, se necesitan nuevas competencias, actitudes y conductas que conduzcan a sociedades más sostenibles.

Los sistemas educativos tienen que responder a esta necesidad a la hora de definir los objetivos y contenidos de aprendizaje pertinentes, introduciendo pedagogías que empoderen a los alumnos e instando a las instituciones a incluir los principios de sostenibilidad en sus estructuras de gestión.

La nueva agenda mundial para el desarroIlo sostenible 2030 refleja claramente esta visión de la importancia de una respuesta educativa apropiada. La educación está explícitamente formulada como un objetivo independiente en el Objetivo de Desarrollo Sostenible número. 
4. Metas e indicadores relacionados con la educación también están incluidos en otros ODS.

La educación de calidad es tanto una meta en sí misma como un medio para lograr todos los otros ODS, porque es parte integral del desarrollo sostenible y un facilitador clave del mismo. Es por ello que la educación representa una estrategia esencial en la consecución de los ODS.

Lo que sí es importante es dejar establecida la relación biunívoca entre salud y educación, se aprecia en diversos acuerdos como se atienden los presupuestos orientados a la EDS, y para los aspectos de salud no reciben la atención adecuada, se re- quiere la sensibilización de los organismos mundiales, nacionales y locales, como se ha demostrado en el punto anterior donde todo lo que involucra a la salud, los aspectos anatómicos, fisiológicos, fisiopatológicos necesitan mayor atención porque si hay problemas en este caso de la esfera visual la educación se verá afectada y más aún si desconoce todos los avances demostrados por la neurociencia en cuanto al desarrollo de las habilidades visuales por señalar un aspecto. A continuación, en el cuadro 2 se muestran artículos que evidencian la interrelación entre el ODS 3 Y el ODS 4.

Cuadro 1. Educación para el desarrollo sostenible y la salud

\begin{tabular}{|c|c|c|}
\hline HALLAZGOS & ARTÍ́CULOS & ANÁLISIS \\
\hline $\begin{array}{l}\text { Como la propia Organización de } \\
\text { Naciones Unidas afirma para lo- } \\
\text { grar los objetivos de desarrollo } \\
\text { sostenible de la Agenda } 2030 \text {, es } \\
\text { necesario garantizar una vida sa- } \\
\text { ludable y promover el bienestar } \\
\text { universal. De hecho, el tercero de } \\
\text { los diecisiete objetivos de desarro- } \\
\text { llo sostenible formulados en } 2015 \\
\text { alude a la salud cuando habla de } \\
\text { la necesidad de garantizar una } \\
\text { vida sana y promover el bienestar } \\
\text { para todos en todas las edades. }\end{array}$ & $\begin{array}{l}\text { El papel de la educación para la } \\
\text { salud en la prevención del VIH/ } \\
\text { sida: una aproximación desde la } \\
\text { educación para el desarrollo en } \\
\text { Centroamérica } \\
\text { (Cobos et,al,2020) }\end{array}$ & $\begin{array}{l}\text { Se debe tomar en cuenta el dere- } \\
\text { cho que asiste a los pueblos indí- } \\
\text { genas y a las comunidades étni- } \\
\text { cas requiere de la implementación } \\
\text { de intervenciones culturalmente } \\
\text { apropiadas, que respeten su cos- } \\
\text { movisión, sus saberes tradiciona- } \\
\text { les, sus formas de organización } \\
\text { social y su diversidad de respues- } \\
\text { tas a la epidemia, los individuos y } \\
\text { las comunidades deben hacerse } \\
\text { responsables directos de la ges- } \\
\text { tión de sus propios estilos de vida. }\end{array}$ \\
\hline
\end{tabular}




\begin{tabular}{|c|c|c|}
\hline $\begin{array}{l}\text { La atención se había centrado en } \\
\text { gran medida en la influencia que } \\
\text { tienen las conductas vinculadas a } \\
\text { los estilos de vida en la prevención } \\
\text { de las enfermedades no transmisi- } \\
\text { bles (ENTs), junto con otros temas } \\
\text { como las enfermedades infeccio- } \\
\text { sas, el alfabetismo para la salud } \\
\text { y la salud medioambiental. Y mi- } \\
\text { rando al futuro, ¿qué temas nos } \\
\text { gustaría leer en la revista de pro- } \\
\text { moción de la salud? Puesto que la } \\
\text { salud de las personas y del plane- } \\
\text { ta se ve continuamente amenaza- } \\
\text { da, es urgente pasar a la acción } \\
\text { concertada para lograr avances } \\
\text { significativos y susceptibles de ser } \\
\text { medidos. }\end{array}$ & $\begin{array}{l}\text { La promoción de la salud en la } \\
\text { era de los Objetivos de Desarrollo } \\
\text { Sostenible (Di Ruggiero,2019) }\end{array}$ & $\begin{array}{l}\text { Existen controversias en cuanto } \\
\text { a las inversiones en promoción } \\
\text { de la salud y en las infraestructu- } \\
\text { ras necesarias. Existen probable- } \\
\text { mente muchas razones para ello: } \\
\text { 1) la relativa falta de inversión en } \\
\text { estudios, programas y políticas } \\
\text { de promoción de la salud en com- } \\
\text { paración con otros campos hace } \\
\text { quesea difícil demostrar a utilidad } \\
\text { a una escala significativa; 2) los } \\
\text { peligros del cortoplacismo favore- } \\
\text { cen la atención en el ahora y ame- } \\
\text { nazan las inversiones más a largo } \\
\text { plazo en prevención y promoción } \\
\text { de la salud (cuando los beneficios } \\
\text { no se perciben como inmediatos); } \\
\text { y 3) la pluralidad de la evidencia } \\
\text { que sustenta el estudio de la pro- } \\
\text { moción de la salud, si bien nece- } \\
\text { saria, puede estar afectando a la } \\
\text { capacidad de defender de mane- } \\
\text { ra convincente y coherente la ne- } \\
\text { cesidad de inversiones futuras. }\end{array}$ \\
\hline $\begin{array}{l}\text { Se requiere priorizar el sector de } \\
\text { la Salud; la calidad del servicio } \\
\text { que se brinda, el cumplimiento } \\
\text { de la ética médica, el logro de la } \\
\text { satisfacción de la población; la uti- } \\
\text { lización eficiente de los recursos, } \\
\text { ahorro y eliminación de gastos in- } \\
\text { necesarios; el fortalecimiento de } \\
\text { las acciones de salud con la par- } \\
\text { ticipación intersectorial y comuni- } \\
\text { taria en la promoción y prevención } \\
\text { para el mejoramiento del estilo de } \\
\text { vida de la población; }\end{array}$ & $\begin{array}{l}\text { Ética ambiental en la educación } \\
\text { política e ideológica para el desa- } \\
\text { rrollo sostenible en Salud (Morales } \\
\text { et,al 2019) }\end{array}$ & $\begin{array}{l}\text { Los seres humanos han encontra- } \\
\text { do en este tipo de problemas un } \\
\text { contenido ético, pues la humani- } \\
\text { dad poco a poco ha tomado con- } \\
\text { ciencia del grave estado en que se } \\
\text { encuentra la naturaleza planetaria, } \\
\text { lo que se le atribuye a la interac- } \\
\text { ción sociedad - entorno ambiental, } \\
\text { o bien hombre - naturaleza, bajo } \\
\text { las condiciones que imponen la } \\
\text { propiedad privada y el mercado } \\
\text { como regentes de la sociedad. }\end{array}$ \\
\hline $\begin{array}{l}\text { La alfabetización para la salud } \\
\text { está vinculada a la alfabetización } \\
\text { y conlleva el conocimiento, la mo- } \\
\text { tivación y las aptitudes para acce- } \\
\text { der, comprender y aplicar la infor- } \\
\text { mación en temas de salud, con el } \\
\text { fin de hacer valoraciones y tomar } \\
\text { decisiones en lo concerniente a te- } \\
\text { mas cotidianos de salud, preven- } \\
\text { ción de enfermedades y fomento } \\
\text { de la salud, con la intención de } \\
\text { mantener o mejorar la calidad de } \\
\text { vida en el transcurso de esta. }\end{array}$ & $\begin{array}{l}\text { Alfabetización para la salud, más } \\
\text { que información. (Canal et.al 2018) }\end{array}$ & $\begin{array}{l}\text { Aquí se pone en evidencia la im- } \\
\text { portancia que tiene la salud para } \\
\text { la promocion de la misma, se re- } \\
\text { quiere de la toma de conciencia } \\
\text { por parte de los interesados, así } \\
\text { como una mayor motivación y el } \\
\text { logro de competencias para acce- } \\
\text { der, entender, evaluar y aplicar a la } \\
\text { salud o entorno }\end{array}$ \\
\hline
\end{tabular}

La atención se había centrado en gran medida en la influencia que

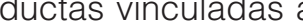
los estilos de vida en la prevención de las enfermedades no transmisibles (ENTs), junto con otros temas como las enfermedades infecciosas, el alfabetismo para la salud y la salud medioambiental. Y misalud de las personas y del planeta se ve continuamente amenaza-

Se requiere priorizar el sector de satisfacción de la población; la utilización eficiente de los recursos, ahorro y eliminación de ge taria en la promoción y prevención para el mejoramiento del estilo de vida de la población;

La alfabetización para la salud mación en temas de salud, con el fin de hacer valoraciones y tomar niente a temantener o mejorar la calidad de
Existen controversias en cuanto de la salud y en las infraestructuestudios, programas y políticas de promoción de la salud en comparación con otros campos hace quesea difícil demostrar a utilidad una escala significativa; 2) los peligros del cortoplacismo favoreplazo en prevención y promoción que sustenta el estudio de la promoción de la salud, si bien necesaria, puede estar afectando a la capacidad de defender de manela ne-

Los seres humanos han encontrado en este tipo de problemas un contenido ético, pues la humanidad poco a poco ha tomado conciencia del grave estado en que se encuentra la naturaleza planetaria, ción sociedad -entorn o bien hombre - naturaleza, bajo las condiciones que imponen la propiedad privada y el mercado como regentes de la sociedad. la promocion de la misma, se requiere de la toma de conciencia por parte de los interesados, así como una mayor motivación y el der entender, evaluar y aplicar a la salud o entorno 
Desde que las Naciones Unidas aprobaron la Agenda 2030, diferentes países, organismos científicos e instituciones internacionales han puesto en marcha estudios de distinta naturaleza con la finalidad de monitorear el progreso hacia

Objetivos de Desarrollo Sostenible (ODS): una revisión crítica (Gomez,2017)
Los ODS mantienen la tradición de acuerdos utópicos promovidos por la ONU, pero sin responsabilidades precisas, lo que facilita su incumplimiento, de ahí las falencias en los presupuestos asignados para la salud no cubran las expectativas requeridas por la población ponibles y revisar las estrategias aplicadas.

Fuente: Artículos revisados Aparicio,2021

\section{Conclusiones}

A través de la revisión se ha mostrado la estrecha relación entre la salud y la educación, representados en la Agenda 2030 como el Objetivo de Desarrollo Sostenible 3 y Objetivo de Desarrollo Sostenible 4, ambos en una relación biunívoca que las mantiene unidas y donde las falencias de una repercuten en la otra, y en todas sus dimensiones.

El procesamiento de la información visual y la oculomotricidad son habilidades visuales vitales para el proceso de lectoescritura, por lo que la salud visual es una parte imprescindible en la Educacion para el desarrollo sostenible y que pueda contribuir con las metas establecidas. Por tanto, se deben aunar los esfuerzos ante los entes gubernamentales para la exigencia de presupuestos y recursos humanos, materiales y tecnológicos, para el fortalecimiento del nivel de Atencion Primaria en Salud, puerta de entrada para la difusión de la importancia de la salud visual.

\section{Bibliografía}

Canal, J; Bertran, Suñer, C\& Soler, R. (2018) Alfabetización para la salud, más que información. Gaceta Sanitaria [online]. 2018, v. 32, n. 1 [Accedido 28 Marzo 2021] ,pp. 8-10. Disponible en: <https://doi.org/10.1016/j.gaceta.2017.07.005>. ISSN 0213-9111. https://doi.org/10.1016/j.gaceta.2017.07.005.

Clínica Cofán (2018). Problemas de visión y bajo rendimiento escolar. Disponible en: https://www. clofan.com/problemas-de-vision-y-bajo-rendimiento-escolar/
Cobos, D; Morón, J \& Castilla, K. (2020) «El papel de la educación para la salud en la prevención del VIH/sida: una aproximación desde la educación para el desarrollo en Centroamérica». Educar, [en línea], 2020, Vol. 56, n. ${ }^{\circ}$ 2, pp. 315-31, https://doi. org/10.5565/rev/educar.1084 [Consulta: 29-032021].

del Álamo Martín, M. T. (2021). La importancia de los registros de pacientes con Enfermedades Raras de la visión para la investigación en ciencias sociales. Araucaria, 23(46). https://doi.org/10.12795/ araucaria.2021.i46.19

Fransoy, M \& Augé, M (2013). Visión y aprendizaje (I) Optometría neurocognitiva en la etapa escolar. Cuadernos científicos del Collegi Oficial d'Òptics Optometristes de Catalunya · N 4 mayo 2013

Morales, L; Morales, M; Estévez, E \& Ramos, A. (2019). Ética ambiental en la educación política e ideológica para el desarrollo sostenible en Salud. Rev Hum Med vol.19 no.3 Ciudad de Camagüey sept.-dic. 2019 Epub 09-Dic-2019

Organización Mundial de la Salud OMS,2019). La OMS presenta el primer Informe mundial sobre la visión. Disponible en. https://www.who.int/es/ news/item/08-10-2019-who-launches-first-worldreport-on-vision

Organización de las Naciones Unidas para la Educación, la Ciencia y la Cultura (UNESCO ,2021) Educación para el desarrollo sostenible. Disponible en: https://es.unesco.org/themes/educacion-desarrollo-sostenible

Organización de las Naciones Unidas. (ONU 2015). 17 objetivos para transformar nuestro mundo. Disponible en: https://www.un.org/sustainabledevelopment/es/

Organización de las Naciones Unidas. (ONU 2017). Qué son los 17 Objetivos de Desarrollo Sostenible y la Agenda 2030. Disponible en: https://www. educo.org/blog/Que-son-los-17-Objetivos-de-Desarrollo-Sostenible 
Peraza de Aparicio, C. X.., González Díaz, E. M., Zurita Barrios, N. Y.., \& Rodríguez Reverol, K. C. (2020). La Salud Visual Infantil Desde la Atención Primaria. Un Caso de Estudio en la Enseñanza de Optometría. Revista Científica Hallazgos21, 5(3), 325-337. Recuperado a partir de https://revistas. pucese.edu.ec/hallazgos21/article/view/479

Pinargote-Valencia, K. (2021). Visual Thinking una alternativa innovadora en los procesos de enseñanza - aprendizaje de Estudios Sociales. Dominio de las Ciencias, 7(1), 3-15. doi: http://dx.doi. org/10.23857/dc. v7i1.1622
Restrepo, G \& Calvachi, L (2021). Neuroeducación y aprendizaje de la lectura Del laboratorio al salón de clase. Neuroeducación y aprendizaje de la lectura. Del laboratorio al salón de clase. JONED. Journal of Neuroeducation. 2021; 1(2); 15-21.

Yuste, R \& Church, G (2014). El nuevo siglo del cerebro. Disponible en: https://www.investigacionyciencia.es/revistas/investigacion-y-ciencia/ el-siglo-del-cerebro-599/el-nuevo-siglo-del-cerebro-12009

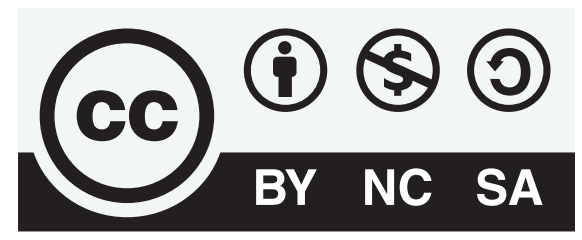

CREATIVE COMMONS RECONOCIMIENTO-NOCOMERCIAL-COMPARTIRIGUAL 4.0.

\section{CITAR ESTE ARTICULO:}

Peraza de Aparicio, C. X. (2021). Sinergia entre la salud visual y la educación para el desarrollo sostenible. RECIMUNDO, 5(1 (Suple), 33-43. https://doi. org/10.26820/recimundo/5.(Suple1).oct.2021.33-43 